\title{
Tuberculosis in medical doctors - a study of personal experiences and attitudes
}

\author{
A Naidoo, S Naidoo, P Gathiram, U Lalloo \\ Department of Family Medicine, Nelson R Mandela School of Medicine, University of KwaZulu-Natal, Durban \\ A Naidoo, MB ChB, MMed \\ S Naidoo, MB ChB, MFamMed, FCFP, PhD \\ P Gathiram, BSc, MSc, PhD
}

Department of Pulmonology, Nelson R Mandela School of Medicine, University of KwaZulu-Natal, Durban U Lalloo, MB ChB, FCP, DOH, MD, FRCP, FCCP

Corresponding author: A Naidoo (ashanthanaidoo@yahoo.com)

\begin{abstract}
Background. The concurrent TB and HIV epidemics in sub-Saharan Africa place all healthcare workers (HCWs) at increased risk of exposure to Mycobacterium tuberculosis.

Aim. This study explores personal experiences, attitudes and perceptions of medical doctors following treatment for TB within the healthcare system.

Method. Sixty-two medical doctors who were diagnosed with and treated for TB during 2007 - 2009 agreed to participate and complete a semi-structured questionnaire.

Results. The response rate was $64.5 \%(N=40)$. The mean age of participants was 33.7 years (standard deviation \pm 10.6$)$. A correct diagnosis of TB was made within 7 days of clinical presentation in $20 \%$ of participants, and was delayed beyond 3 weeks in $52.5 \%$. Non-routine special investigations and procedures were performed in 26 participants. Complications following invasive procedures were reported by 8 participants. Multi-drug resistant TB (MDR-TB) was diagnosed in 4 participants. Nineteen considered defaulting on their treatment because of drug side-effects. The majority $(n=36)$ expressed concerns regarding lack of infection control at the workplace, delays in TB diagnosis and negative attitudes of senior medical colleagues and administrators. Ninety per cent of participants indicated that their personal illness experiences had positively changed their professional approach to patients in their current practice.

Conclusion. The inappropriate delays in diagnosis in a large number of participants, coupled with a number of negative personal perceptions towards their treatment, are cause for concern. The results further amplify the need for improved educational and awareness programmes among all healthcare personnel (including hospital administrators), adherence to national health guidelines, effective infection control measures, pre- and post-employment screening in all HCWs, and changes in attitudes on the part of senior medical colleagues and administrators.

S Afr Med J 2013;103(3):176-180. DOI:10.7196/SAMJ.6266
\end{abstract}

Tuberculosis (TB) has reached epidemic proportions in sub-Saharan Africa, the incidence in South Africa (SA) having risen from 556 cases per 100000 population in 2002 to 981 per 100000 population in 2010. ${ }^{[1]}$ This epidemic is fuelled by the HIV epidemic. ${ }^{[1-3]} \mathrm{SA}$ is ranked among the top 3 TB-incidence countries in the world, with an extremely high drug resistance rate (both multi-drug and extensively drug-resistant) despite being one of the most resourced countries in Africa. Occupational exposure to TB constitutes a major health hazard for all healthcare workers (HCWs) throughout the world, and especially in low-income and resource-constrained countries and settings. ${ }^{[4,5]}$ A study of state hospital records in KwaZulu-Natal (KZN) Province for the period January 1999 - June 2004 showed the 'incidence of TB in HCWs to be alarmingly high (mean incidence being 1133 per 100000 ) particularly in the younger age groups (25 29 years)' with the authors concluding that poor treatment outcomes were cause for concern. ${ }^{[6]}$

The risk of developing TB among HCWs depends on factors such as occupational category, age and use of TB infection control measures in the workplace. ${ }^{[7]}$ While a number of general population studies have been conducted globally on the attitudes and psychological impact of contacting $\mathrm{TB},{ }^{[4,8-10]}$ little or no work has been done among HCWs generally, and particularly among doctors who are at greater risk of exposure than the general population. A qualitative study on the impact of drug-resistant TB on 5 medical doctors in SA found that 4 of them experienced adverse effects owing to medication, which in some continued for several years after treatment was completed. ${ }^{[2]}$ This study furthermore documented prolonged morbidity, psychological disturbances, poor infection control and support structures in the working environment, and doctors leaving the profession.

Our study investigated the personal experiences of medical doctors treated for $\mathrm{TB}$, and their attitudes towards their diagnosis and management.

\section{Methods}

This descriptive cross-sectional study was conducted in 2010 among medical doctors working in the public and private sectors in KZN Province, SA, who had been diagnosed and treated for TB during 2007 - 2009. Institutional ethical approval was granted by the University of KwaZulu-Natal (reference BF 097/09) and the KZN Provincial Department of Health.

Relevant information concerning the study was provided at meetings of representatives of medical doctor groups held at 3 major 
centres in KZN (Durban, Empangeni and Pietermaritzburg) during 2010. All medical doctors who had been diagnosed and treated for TB during 2007 - 2009 were invited to participate. Additionally, the study was advertised via the secretariat of each medical group. Those interested in participating were requested to contact the lead researcher (AN). Sixty-two medical doctors working in these 3 centres responded to the advertisements and volunteered to participate. Questionnaires were then distributed to all respondents on receipt of written informed consent.

Data were collected using a self-administered semi-structured questionnaire comprising both open and closed-ended questions. The questionnaire was piloted with 5 medical doctors who had TB prior to 2007, and modified prior to distribution to participants. Confidentiality and anonymity were maintained at all times, and participants were required to return the questionnaires without identifiers.

Data were analysed using Statistical Software Package for the Social Sciences (SPSS3), version 18. Frequencies and percentages (including mean and standard deviation where appropriate) were calculated to describe the categorical variables; statistical significance of associations between variables was assessed using Pearson's chisquare tests.

\section{Results}

Forty of the 62 respondents completed and returned the questionnaires - a response rate of $64.5 \%$. The study sample comprised 21 men and 19 women. The mean age of participants was $33.67 \pm 10.63$ years. The socio-demographic profiles of all participants are shown in Table 1. There were 34 Indians, 3 blacks and 3 whites among the participants. The majority $(n=38)$ were employed in state hospitals, of whom 27 (67.5\%) were employed in specialist designated regional or tertiary state sectors, and the remainder $(27.5 \%)$ in primary care clinics and district hospital facilities. Two were self-employed and in private general practice. Sixty-five per cent had worked in medical disciplines and $27.5 \%$ in a surgical discipline in public hospitals prior to being diagnosed with TB. Only 2 of the participants worked either in a TB clinic or TB in-patient ward. Ten participants were still receiving TB treatment at the conclusion of the study.

There were no statistically significant gender differences for any of the variables studied. The most common presenting symptoms and the investigations performed at initial presentation in public and/or private hospitals are listed in Tables 1 and 2 respectively.

Sputum microscopy was requested for 28 (70\%) participants, and chest radiographs performed on $38(95.0 \%)$ by the relevant occupational health clinics at the site of employment in the public health sector. Fifteen participants (37.5\%) self-referred to specialist physicians in the private sector and underwent chest computerised axial tomography (CAT) scans. Other investigations or diagnostic procedures undertaken in the private sector included upper oesophagoscopy (in a participant complaining of dysphagia), lung function testing, bronchoscopy, tissue biopsy (of pleura, lymph node and lung), magnetic resonance imaging (MRI) scans and CAT angiograms.

Eight $(20.0 \%)$ of the participants reported the development of complications as a result of diagnostic procedures (Table 2). The complications were haemoptysis and pleuritic chest pain following bronchoscopy, cellulitis at the biopsy site of the lesion, development of a chest wall abscess at the biopsy site, a chronic draining sinus from a lymph node biopsy site, and injury to the neurovascular bundle following insertion of an intercostal chest drain and a pleural biopsy.
Table 1. Socio-demographic profile and presenting symptoms $(n=40)$

\begin{tabular}{|c|c|c|}
\hline \multirow[b]{2}{*}{ Variable } & \multicolumn{2}{|c|}{ Total } \\
\hline & $n$ & $\%$ \\
\hline Number of participants, $n$ & 40 & 100.0 \\
\hline \multicolumn{3}{|l|}{ Gender, $n$} \\
\hline Male & 21 & 52.5 \\
\hline Female & 19 & 47.5 \\
\hline \multicolumn{3}{|l|}{ Age (years), $n$} \\
\hline $3-30$ & 21 & 52.5 \\
\hline $1-40$ & 13 & 32.5 \\
\hline $41-50$ & 1 & 2.5 \\
\hline $51-60$ & 5 & 12.5 \\
\hline \multicolumn{3}{|l|}{ Race, $n$} \\
\hline Black & 3 & 7.5 \\
\hline Indian & 34 & 85.0 \\
\hline White & 3 & 7.5 \\
\hline \multicolumn{3}{|l|}{ Current employment, $n$} \\
\hline $\begin{array}{l}\text { Public sector: PHC and district } \\
\text { hospital }\end{array}$ & 11 & 27.5 \\
\hline Specialty level (levels $2-4$ ) & 27 & 67.5 \\
\hline Private sector (self-employed) & 2 & 5.0 \\
\hline \multicolumn{3}{|l|}{$\begin{array}{l}\text { Discipline ever worked in prior to } \\
\text { diagnosis, } n\end{array}$} \\
\hline Medical & 29 & 72.5 \\
\hline Surgical & 8 & 20.0 \\
\hline General practice (self-employed) & 2 & 5.0 \\
\hline Non-disclosure & 1 & 2.5 \\
\hline \multicolumn{3}{|l|}{ Final diagnosis, $n$} \\
\hline Pulmonary TB & 32 & 80.0 \\
\hline MDR-TB (pulmonary) & 4 & 10.0 \\
\hline Extra-pulmonary TB & 8 & 20.0 \\
\hline \multicolumn{3}{|l|}{ Baseline presenting symptoms, $n$} \\
\hline Malaise & 22 & 55.0 \\
\hline Night sweats & 21 & 52.5 \\
\hline Cough & 19 & 47.5 \\
\hline Weight loss & 20 & 50.0 \\
\hline Chest pain & 14 & 35.0 \\
\hline Lymphadenopathy & 12 & 30.0 \\
\hline Fever & 9 & 22.5 \\
\hline Other symptoms & 25 & 62.5 \\
\hline
\end{tabular}

Thirty-two participants (80.0\%) were finally diagnosed as having pulmonary TB, $4(10.0 \%)$ of whom were found to have multi-drug resistant TB. The remaining 8 participants were diagnosed with extra-pulmonary TB (Table 1).

In only $52.5 \%(n=21)$ (Table 3$)$ of participants was TB diagnosed on initial presentation. In $20.0 \%(n=8)$, the diagnosis was established within 7 days of seeking treatment (Table 4). Eleven participants were diagnosed between weeks 2 and 3, and 21 (52.5\%) beyond day 21. Reasons for delays in diagnosis are listed in Table 3. Thirty-five 
Table 2. Initial investigations and complications

\begin{tabular}{lll}
\hline & \multicolumn{2}{c}{ Participants } \\
\cline { 2 - 3 } Investigations & $\boldsymbol{n}$ & $\%$ \\
\hline Chest X-ray & 38 & 95.0 \\
Sputum & & \\
$\quad$ Microscopy & 28 & 70.0 \\
Culture & 23 & 57.5 \\
$\quad$ Sensitivity & 17 & 42.5 \\
CAT scan (chest) & 15 & 37.5 \\
Tissue biopsy & & \\
$\quad$ Microscopy & & \\
Culture & 14 & 35.0 \\
Pleural fluid & 9 & 22.5 \\
$\quad$ Chemistry & & \\
Microscopy & & \\
Culture & 8 & 20.0 \\
$\quad$ Quantiferon Gold in-tube test & 7 & 17.5 \\
$\quad$ Other investigations & 7 & 17.5 \\
$\quad$ Complications as a result of & 3 & 7.5 \\
procedures conducted & 8 & 20.0 \\
\end{tabular}

Table 3. Time lag from initial presentation to TB diagnosis

\begin{tabular}{lll}
\hline & \multicolumn{2}{c}{ Participants } \\
\cline { 2 - 3 } & $\boldsymbol{n}$ & $\%$ \\
\hline Time delay to TB diagnosis (days) & & \\
$\quad<8$ & 11 & 20.0 \\
$8-21$ & 21 & 52.5 \\
$\quad 22-59$ & & \\
$\quad$ Initial diagnosis (TB) & 21 & 52.5 \\
$\quad$ Correct & 19 & 47.5 \\
$\quad$ Wrong & & \\
Perceived cause of delay in diagnosis & 5 & 12.5 \\
$\quad$ Inappropriate help-seeking behaviour & 8 & 20.0 \\
$\quad$ Healthcare provider issues & &
\end{tabular}

per cent (14) of all participants suggested that the delays in diagnosis were inappropriate, further analysis revealing that 5 participants (12.5\%) admitted to their own delayed and/or inappropriate healthseeking behaviour. Eight participants (20.0\%) felt that their caregiver had either delayed or omitted investigation. Of the 40 participants, 19 were initially incorrectly diagnosed (Table 3 ).

A total of 84 iatrogenic side-effects (Table 4 ) were experienced by $82.5 \%(n=33)$ of the participants. Nine participants who developed severe iatrogenic side-effects self-medicated with homeopathic and complementary therapy while on concurrent anti-TB therapy.

Participants were also requested to indicate their views on 6 leading statements based on a Likert scale relating to their diagnosis, investigations and treatment (Table 5). A number of participants agreed that medical doctors received preferential consideration for specialised diagnostic procedures $(n=30(75 \%))$, and also that they generally received preferential treatment $(n=18(45 \%))$, compared with the rest of the population. The majority $(n=36(90 \%))$ agreed with the statement that their personal experiences as patients with TB
Table 4. Side-effects of prescribed medications

\begin{tabular}{lll}
\hline & \multicolumn{2}{c}{ Total } \\
\cline { 2 - 3 } Side-effect & $\boldsymbol{n}$ & $\%$ \\
\hline Abdominal pain & 10 & 25.0 \\
Arthralgia & 5 & 12.5 \\
Diarrhoea & 5 & 12.5 \\
Dizziness & 1 & 2.5 \\
Drowsiness & 1 & 2.5 \\
Gout & 1 & 2.5 \\
Headache & 1 & 2.5 \\
Hepatitis & 3 & 7.5 \\
Insomnia & 2 & 5.0 \\
Malaise & 9 & 22.5 \\
Metallic taste & 2 & 5.0 \\
Myopathy & 2 & 5.0 \\
Nausea, vomiting & 21 & 52.5 \\
Peripheral neuropathy & 7 & 17.5 \\
Photophobia & 2 & 5.0 \\
Skin rash & 7 & 17.5 \\
& &
\end{tabular}

had influenced them to modify their attitudes and clinical approaches to their current patients, including becoming more empathic towards their patients.

One participant stated that she regretted choosing clinical medicine as a career option, and has since found employment elsewhere in a laboratory facility without patient contact to minimise further risk. Another expressed similar feelings and stated that he was treated inappropriately by his work colleagues during his illness, being criticised for taking sick leave and required to make up lost work-hours. This sentiment was echoed by other participants who reported their belief that senior medical supervisors considered that sick leave was a privilege and not an entitlement. One participant complained that his confidentiality was not maintained; he subsequently sought employment without patient contact.

One participant felt 'angry' when having to treat patients who were infected with TB and HIV and admitted to feelings of resentment towards them as he felt they were 'responsible' for his illness. 'Having $\mathrm{TB}$ has been one of the most debilitating experiences of my life, expressed one of the participants. Another participant lamented the attitudes of other colleagues and said, '... our task as doctors is to assist with healing others. It hurts when our own well-being is jeopardised through an illness (that we have contracted in trying to provide a service to others), and our own colleagues and our management show an uncaring attitude towards us!'

\section{Discussion}

The present study is the first in SA, with its high TB and HIV burden, to report the experiences attitudes and perceptions of medical doctors (in the healthcare system) who contracted TB and their attitudes and perceptions towards their illness. The study has shown that, despite their accessing appropriate occupational health clinics, the diagnosis of TB was delayed beyond day 8 in the majority, and that they received sub-optimal TB care compared with national and international treatment guidelines. ${ }^{[1]}$ 
Table 5. Reflective responses on diagnosis and treatment

\begin{tabular}{|c|c|c|c|c|c|}
\hline Statement & $\begin{array}{l}\text { Strongly disagree } \\
n\end{array}$ & $\begin{array}{l}\text { Disagree } \\
n\end{array}$ & $\begin{array}{l}\text { Neutral } \\
n\end{array}$ & $\begin{array}{l}\text { Agree } \\
n\end{array}$ & $\begin{array}{l}\text { Strongly agree } \\
n\end{array}$ \\
\hline Found period of treatment difficult to endure & 4 & 4 & 5 & 20 & 7 \\
\hline Considered defaulting on pharmacotherapy & 17 & 9 & 1 & 10 & 3 \\
\hline $\begin{array}{l}\text { I modified my pharmacotherapy to suit my } \\
\text { personal needs }\end{array}$ & 14 & 15 & 0 & 10 & 1 \\
\hline $\begin{array}{l}\text { Medical doctors are more likely to have access to } \\
\text { specialised diagnostic procedures than the rest of } \\
\text { the population }\end{array}$ & 1 & 8 & 1 & 18 & 12 \\
\hline $\begin{array}{l}\text { Medical doctors are given preferential medical } \\
\text { treatment }\end{array}$ & 2 & 11 & 9 & 14 & 4 \\
\hline $\begin{array}{l}\text { Personal experience has changed my approach to } \\
\text { patients }\end{array}$ & 0 & 1 & 3 & 24 & 12 \\
\hline
\end{tabular}

Many of our study participants were in the younger age group and employed within clinical departments in the public healthcare system before seeking help for their illness. Contrary to expectation, the overwhelming majority did not work in TB wards or TB clinics. It is probable that they acquired TB from patients with whom they were in close clinical contact, given that the majority of patients with TB usually first access general medical departments where doctors and nurses are the primary care givers. ${ }^{[2,6,12]}$

Our study found, surprisingly, that a large number of doctors had not taken seriously the cluster of symptoms that included cough and night sweats (that are generally accepted as being suggestive of TB infection), so delaying diagnosis and definitive treatment. However, the majority of participants in this study presented with nonspecific symptoms and signs, and therefore would have found it difficult to differentiate these from workrelated fatigue or other mild illnesses. As one participant stated, 'I neglected the symptoms due to the pressures of work ... stress, physical exhaustion, 10 - 12 calls per month, sleep deprivation and inappropriate diet.' Moreover, a few participants indicated that 'many doctors may be reluctant to admit that they are ill and may be especially unwilling to acknowledge that their ill health is affecting their performance at work.' Fear of stigmatisation in social and professional circles, which resulted in delayed helpseeking behaviour, have also been reported. ${ }^{[13]}$ The World Health Organization identifies two main categories, which cause delay from onset of symptoms to diagnosis of $\mathrm{TB}$, as patient delays and health system delays. ${ }^{[14]}$ It has been recommended that the time elapsing between the patient being seen in the health care system and diagnosis should not exceed 24 hours. ${ }^{[15]}$ In our study, multiple health system problems such as failure to adhere to standard treatment guidelines by clinical staff, delayed laboratory confirmation of tests, incorrect diagnosis and failure to treat empirically following clinical presentation, coupled with patient factors already described, contributed to delays exceeding 3 weeks in diagnosis of the disease in the majority (about 58\%) of our participants. Similar delays have been reported in other studies involving the general population. ${ }^{[16,17]}$

If misdiagnosis, long delays in making the correct diagnosis and complications owing to procedures are experienced by medical doctors akin to those described in this study, the situation may be expected to be even worse among the general population. Furthermore, many participants complained of lack of infection control measures in their workplaces, including simple costeffective measures that would have been protective. Herein may lie, in part, an explanation of why SA has such an unmanageable TB epidemic.

Not surprisingly, most doctors received preferential care by fellow medical colleagues, and particularly specialist physicians, to whom they were referred or self-referred. Despite this, their care was suboptimal when compared with the standard guidelines. ${ }^{[1]}$

The paucity of studies related to illness and management perceptions, stigmatisation and denialism among medical doctors infected with TB has made comparisons difficult. However, studies conducted among the general population on personal experiences following TB infection reveal similar findings. Denial by patients of having contracted or their suffering from TB has been an ongoing problem. ${ }^{[8,18]}$ TB-related stigma has been shown to worsen the quality of life of patients, affecting their health and healthseeking behaviour. ${ }^{[19]}$ Certain social consequences (unemployment, homelessness, imprisonment and poverty) and psychological effects (low morale, depressed mood, mood swings and low confidence in medical staff) all potentially account for poor adherence to treatment and inappropriate help-seeking behaviour. ${ }^{[18,20]}$ Patients who were not adequately educated about the cause of TB, and who felt embarrassed about having contracted the disease, combined with negative attitudes on the part of healthcare staff, discouraged them from seeking early treatment. ${ }^{[10]}$

Tests such as chest X-rays and sputum analysis, which are accepted to be part of the standard care of practice in the national healthcare system, ${ }^{[3,11]}$ were not conducted in all participants in our study. It is possible that participants who could not produce sputum were sent for alternative tests. Because these tests were then found to be negative in the majority of participants, caregivers might have opted for a variety of costly investigations such as Quantiferon Gold in-tube test, chest CT scans (33.5\%), bronchoscopy, mediastinoscopy etc., which are not normally available to the general public. The Quantiferon Gold in-tube test has been found to have a low sensitivity in the diagnosis of active $\mathrm{TB}^{[21]} \mathrm{A}$ number of participants in this study agreed that medical doctors are generally given preferential treatment by their colleagues and are more likely to access specialised levels of care than the general population, and that the search for a diagnosis is amplified when the patient is a medical doctor. However, the low sensitivity and specificity of many of the tests appears not to have been taken into account.

Strict adherence to anti-TB therapy forms the cornerstone of the nationally accepted clinical guidelines in TB management. ${ }^{[3]}$ Clinicians are expected to spend a significant amount of time counselling patients on adherence. It is therefore disconcerting that a large number of 
participants displayed varying responses and attitudes to statements relating to adherence. Thirteen (32.5\%) participants considered defaulting on their treatment, and a further 11 (27.5\%) modified their therapy to suit their personal needs. Twenty-seven (67.5\%) participants admitted to difficulty in enduring their treatment, perhaps because of side-effects commonly associated with anti-TB drugs, and because of concomitant high stress levels and varying levels of depression. Risk factors for defaulting on treatment have been identified in a number of other studies, ${ }^{[22-24]}$ and include side-effects of medication and not being given a choice of treating doctor; long waiting times and problems with health facilities were considered to be additional potential risk factors for non-adherence to therapy.

This study produced the positive finding that most participants were humbled by their own experiences and since became more patient-centred in their consultations. Similar findings have been reported in other studies, where medical doctors felt that their personal experiences have helped them to better empathise and communicate with patients. ${ }^{[25]}$ However, a minority of participants felt that the high burden of disease and increased burden of care by a limited and constrained medical workforce militated against a change in professional behaviour towards patients.

\section{Study limitations}

Notwithstanding the relatively good response rate of $64.5 \%$ shown in our study, ${ }^{[26]}$ major shortcomings in this study included the relatively small sample size and selection bias resulting in a 'skewed' sample. The low sample size might have been influenced by several factors, e.g. restriction of the study to recent cases only, and fears of stigmatisation and victimisation. Additionally, only a minority (30.8\%) of doctors from the primary healthcare sector of the public healthcare system volunteered to participate. Our data may therefore not be representative of the actual prevailing burden of TB among medical doctors working in primary care and rural settings. Furthermore, sample selection bias caused by recruitment of participants from selected areas could have skewed the demographic data.

Shortcomings were also identified in the design of the questionnaire used in the study; these included failure to explore certain demographic and illness data such as urban v. rural setting, access to specialist care in public or private facilities, and time lag from symptoms to help-seeking behaviour.

The results of this study, therefore, cannot be generalised to the broader population of medical doctors in SA, but do serve to alert colleagues to the real risks of contracting TB in the course of healthcare work.

\section{Conclusion}

The negative effect of TB infection on medical doctors is a cause for concern and may mirror a sub-optimal standard of care delivered to patients. The excessive delays before diagnosis in a large number of study participants, coupled with a number of negative personal perceptions about TB diagnosis and treatment, are disconcerting. This study emphasises the need for improved educational and awareness programmes for all healthcare personnel, including hospital administrators, and changes in attitudes on the part of senior medical colleagues and administrators towards medical doctors with $\mathrm{TB}$. There is a need also for strict adherence to national treatment guidelines, and effective infection control measures. A case can be made for pre- and post-employment screening of all HCWs.

Acknowledgements. We thank Ms Tonya Esterhuizen and Mr Stephan van der Linde, of the Biostatistics Department, University of KwaZuluNatal.

\section{References}

1. WHO. TB Data. Geneva: World Health Organization, 2012. http://www.who.int/tb/data (accessed 23 January 2012).

2. Padayatchi N, Daftary A, Moodley T, Madansein R, Ramjee A. Case series of the long-term psychosocial impact of drug-resistant tuberculosis in HIV-negative medical doctors. Int J Tuberc Lung Dis 2010;14:960-966

3. National Department of Health. The South African Tuberculosis Control Programme. Practical Guidelines. Pretoria: National Department of Health, 2007.

Deribew A, Tesfaye M, Hailmichael Y, et al. Tuberculosis and HIV co-infection: its impact on quality of life. Health Qual Life Outcomes 2009;7:105.

5. Galgalo T, Dalal S, Cain KP, et al. Tuberculosis risk among staff of a large public hospital in Kenya. In J Tuberc Lung Dis 2008; 12:949-954

6. Naidoo S, Jinabhai CC. TB in health care workers in KwaZulu-Natal, South Africa. Int J Tuberc Lung Dis 2006;10:676-682.

7. Alonso-Echanove J, Granich RM, Laszlo A, et al. Occupational transmission of Mycobacterium tuberculosis to health care workers in a university hospital in Lima, Peru. Clin Infect Dis 2001;33:589596. [http://dx.doi.org/10.1086/321892]

8. Karim F, Johansson E, Diwan VK, Kulane A. Community perceptions of tuberculosis: A qualitative exploration from a gender perspective. Public Health 2011;125:84-89.

9. Zhang S-R, Yan H, Zhang J-J, Zhang T-H, Li X-H, Zhang Y-P. The experience of college students with pulmonary tuberculosis in Shaanxi, China: a qualitative study. BMC Infect Dis 2010;10:174

10. Rundi C. Understanding tuberculosis: Perspectives and experiences of the people of Sabah, Eas Malaysia. J Health Popul Nutr 2010;28:114-123.

1. National Department of Health. National Tuberculosis Management Guidelines 2009. Pretoria National Department of Health, 2009

12. O’ Donnell MR, Jarand J, Loveday M, et al. High incidence of hospital admissions with multidru resistant and extensively drug resistant tuberculosis among South African health care workers. An Intern Med 2010;153:516-522.

13. Sexton J, Thomas E, Helmreich R. Error, stress and teamwork in medicine and aviation: cross sectiona surveys. Journal of Human Performance in Extreme Environments 2001;6:6-11.

14. World Health Organization. Diagnostic and Treatment Delay in Tuberculosis. An In-Depth Analysis of the Health-Seeking Behaviour of Patients and Health System response in seven Countries of the Eastern Mediterranean Region. WHO-EM/TDR/009/E Geneva: World Health Organization, 2006 http://www.emro. who. int/dsaf/dsa710 pdf (accessed 23 October 2012)

15. Major Mde L, Guerra RL, Cailleaux-Cezar M, Golub JE, Conde MB. Time from symptom onset to the intiation of treatment of pulmonary tuberculosis in a city with a high incidence of the disease. J B as Pneumol 2012;38:202-209.

16. Paul D, Busireddy A, Nagaraja SB, et al. Factors associated with delays in treatment initiation after tuberculosis diagnosis in two districts of India. PLoS One 2012;7:e39040. [http://dx.doi.org/10.1371/ journal.pone.0039040

17. Ndeikoundam Ngangro N, Ngarhounoum D, Ngangro MN, et al. Pulmonary tuberculosis diagnostic delays in Chad: a multicenter, hospital-based survey in Ndjamena and Moundou. BMC Public Health 2012;12:513. [http://dx.doi.org/10.1186/1471-2458-12-513]

18. Jakubowiak WM, Bogorodskaya EM, Borisov SE, Danilova ID, Lomakina OB, Kourbatova EV. Impac of socio-psychological factors on treatment adherence of TB patients in Russia. Tuberculosis (Edinb) 2008:88:495-502.

19. Weiss MG, Somma D, Karim F, et al. Cultural epidemiology of TB with reference to gender in Bangladesh, India and Malawi. Int J Tuberc Lung Dis 2008;12:837-847.

20. Shin S, Munoz M, Espiritu B, et al. Psychosocial impact of poverty on antiretroviral nonadherence amon HIV-TB coinfected patients in Lima, Peru. J Int Assoc Physicians AIDS Care (Chic) 2008;7:74-81.

21. Legesse M, Ameni G, Mamo G, Medhin G, Bjune G, Adebe F. Performance of QuantiFERON-TB

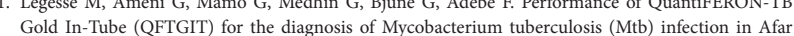
Pastoralists, Ethiopia. BMC Infectious Diseases 2010;10:354. [http://dx.doi.org/10.1186/1471-233410-354]

22. Rashid AK, Rahmah MA. Treatment related risk factors associated with the default of depression treatment among the elderly - - a case control study. The Open Geriatric Medicine Journal 2010;3:11-16. 3. van den Boogaard J, Boeree MJ, Kibiki GS, Aarnoutse RE. The complexity of the adherence-respons relationship in tuberculosis treatment: why are we still in the dark and how can we get out? Trop Me Int Healh 2011,16.693-698. [hlp.//kx.doi.org/10.1111/) 1365-3156.2011.02755.x]

, Oguya $\mathrm{F}$ Factors associated with defaul from treatment among tuberculosis patients in Nairobi province, Kenya: a case control study. BMC

Public Health 2011;11:696. [http://dx.doi.org/10.1186/1471-2458-11-696]
25. Woolf K, Cave J, McManus C, Dacre JE. "It gives you an understanding you can't get from any book." The relationship between medical students' and doctors' personal illness experiences and their performance: a qualitative and quantitative study. BMC Medical Education 2007;7:50. [http://dx.doi. org $/ 10.1186 / 1472-6920-7-50)$

26. Grava-Gubins I, Scott S. Effects of various methodologic strategies. Survey response rates among Canadian physicians and physicians-in-training. Can Fam Physician 2008;54:1424-1430

Accepted 4 November 2012. 